\title{
Promising Mid-term Results With a Cup-cage Construct for Large Acetabular Defects and Pelvic Discontinuity
}

\author{
Tomas Amenabar MD, Wael A. Rahman MD, Bandar M. Hetaimish MD, \\ Paul R. Kuzyk MD, Oleg A. Safir MD, Allan E. Gross MD
}

Published online: 25 February 2015

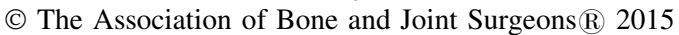

\begin{abstract}
Background Restoring normal anatomy and achieving stable fixation of the acetabular component can be especially challenging when the surgeon must deal with severe acetabular defects and/or pelvic discontinuity. The cupcage (CC) construct, where an ilioischial cage is cemented within a biologically fixed porous metal cup, has emerged as an excellent option to treat such challenges.

Questions/purposes We sought to determine (1) mid-term Kaplan-Meier survival; (2) clinical outcomes based on Merle d'Aubigné-Postel scores; (3) radiological outcomes

One of the authors certifies that he (AEG), or a member of his immediate family, has or may receive payments or benefits, during the study period, an amount of less than USD 10,000 as a consultant from Zimmer Inc (Warsaw, IN, USA).

All ICMJE Conflict of Interest Forms for authors and Clinical Orthopaedics and Related Research ${ }^{\circledR}$ editors and board members are on file with the publication and can be viewed on request.

Clinical Orthopaedics and Related Research ${ }^{\circledR}$ neither advocates nor endorses the use of any treatment, drug, or device. Readers are encouraged to always seek additional information, including FDAapproval status, of any drug or device prior to clinical use.

Each author certifies that his or her institution approved the human protocol for this investigation, that all investigations were conducted in conformity with ethical principles of research, and that informed consent for participation in the study was obtained.
\end{abstract}

T. Amenabar, W. A. Rahman, B. M. Hetaimish

Adult Joint Reconstruction, Mount Sinai Hospital, University of

Toronto, Toronto, ON, Canada

P. R. Kuzyk, O. A. Safir, A. E. Gross

Division of Arthroplasty, Orthopaedic Surgery Department,

Mount Sinai Hospital, Toronto, ON, Canada

T. Amenabar $(\square)$

Orthopaedic Surgery Department, Mount Sinai Hospital, 600

University Avenue, Suite 476A, Toronto, ON M5G 1X5, Canada

e-mail: tomasamenabar@gmail.com based primarily on construct migration; and (4) the complication rate for a series of $67 \mathrm{CC}$ procedures performed at our institution.

Methods All hip revision procedures between January 2003 and March 2012 where a CC was used (with the exception of tumor cases or acute fracture; four total cases) that had a minimum 2-year followup and that had been seen within the last 2 years were included in this retrospective review. Acetabular bone loss and presence of pelvic discontinuity were assessed according to the Gross classification. Sixty-seven CC procedures with an average followup of 74 months (range, 24-135 months; SD, 34.3) months were identified; 26 of 67 (39\%) were Gross Type IV and 41 of 67 (61\%) were Gross Type V (pelvic discontinuity). Postoperative clinical and radiological evaluation was done annually. Merle d'Aubigné-Postel scores were recorded and all radiographs were compared with the 6-week postoperative radiographs to evaluate for radiographic loosening or migration. Failure was defined as revision surgery for any cause, including infection.

Results The 5-year Kaplan-Meier survival rate with revision for any cause representing failure was 93\% (95\% confidence interval [CI], 83.1-97.4), and the 10-year survival rate was $85 \%(95 \% \mathrm{CI}, 67.2-93.8)$. The Merle d'Aubigné-Postel score improved significantly from a mean of 6 preoperatively to 13 postoperatively ( $\mathrm{p}<0.001)$. Four $\mathrm{CC}$ had nonprogressive radiological migration of the ischial flange and they remain stable.

Conclusions We believe that the CC construct is a suitable choice to treat chronic pelvic discontinuity; it also remains a reliable option for the treatment of severe acetabular bone defects if stable fixation cannot be obtained through the use of a trabecular metal cup with or without augments.

Level of Evidence Level IV, therapeutic study. 


\section{Introduction}

Acetabular revision surgery is a complex procedure that may present several problems to the arthroplasty surgeon. The main goals of acetabular revision are to restore normal anatomy (ie, placing the acetabular component at the true hip center of rotation) and to achieve stable fixation of the acetabular component. Achieving these goals is challenging when the surgeon must deal with large acetabular defects and/or pelvic discontinuity $[13,21]$.

Stable fixation may be achieved by using cementless acetabular components with screws if the contact of the component with the host bone is more than 50\% [22]. Implants in these optimal revision settings have shown excellent long-term survivorship ranging from $95 \%$ to $98 \%$ at 10 years $[8,9,32]$. Highly porous metal implants such as Trabecular Metal $^{\text {TM }}$ (TM) (Zimmer Inc, Warsaw, IN, USA) cups that offer improved bone ingrowth and biomechanical properties [3, 5, 14, 21, 33] have also shown encouraging results for acetabular revision [1, 17, 18, 29]. However, it may be difficult or impossible to achieve stability, even with these highly porous metal implants, if the acetabular defect is large, bone quality is poor, there is limited host bone contact, or there is pelvic discontinuity. These complex situations have traditionally been treated with ilioischial cages. Although ilioischial cages provide excellent initial stability, their middle- to long-term failure rates are high as a result of lack of biologic fixation [12, 16, 23, 25, 27, 30].

The cup-cage construct has emerged as a viable option to treat the aforementioned difficulties. This construct consists of a $\mathrm{TM}^{\mathbb{R}}$ cup typically secured with screws with an ilioischial cage cemented within the cup. The cage provides initial stability to the cup by shielding it from mechanical forces. This allows bone to grow within the porous $\mathrm{TM}^{\mathbb{R}}$ cup and biologic fixation to take place, giving the entire construct its long-term stability [15].

The main purpose of this study was to determine midterm Kaplan-Meier survival. Our secondary objectives were to report the clinical outcomes based on Merle d'AubignéPostel scores, radiological outcomes based primarily on construct migration, and complication rate for a series of 67 cup-cage procedures performed at our institution.

\section{Patients and Methods}

\section{Patient Inclusion and Data Collection}

Research and ethics board approval was obtained from our institution. A retrospective review of our surgical database from January 2003 to March 2012 was performed to identify all total hip revision surgeries in which a cup-cage construct was used that had a minimum followup of
2 years. The exclusion criterion was hip surgery because of a bone tumor. All patients were assessed clinically and with radiographic images before surgery. This typically included standard hip, AP pelvis, and Judet oblique views as well as CT scans in some cases.

Seventy-one cup-cages in 68 patients were included in the study. We were unable to locate four patients; therefore, 67 cup-cages in 64 patients were available for followup. Fifty patients (78\%) were female and 14 (22\%) were male. The average age at the time of the cup-cage surgery was 66 years (range, $30-86$ years; SD, 13.1). The most common reason for the initial revision surgery requiring the cup-cage construct was a loose cup (Table 1). The average followup was 74 months (range, 24135 months; SD, 34.3).

The acetabular bone loss and the presence of pelvic discontinuity were determined intraoperatively after removal of the previous components. The acetabular bone loss was classified according to the Gross classification [26]. The revisions requiring a cup-cage were either Type IV, which is an uncontained (segmental) loss of bone stock involving $>50 \%$ of the acetabulum and affecting both columns (26 hips [39\%]), or Type V, defined as an acetabular defect in association with pelvic discontinuity (41 hips [61\%]). Defects classified as Type IV or V according to Gross would correspond to Paprosky Type IIIA or III B depending on whether pelvic discontinuity is present. Three different cages were used for the cup-cage constructs included in the study: two cages were $\mathrm{ZCA}^{\circledR}$ (Zimmer Inc), nine cages were Burche-Schneider (Sulzer Orthopedics Ltd, Winterthur, Switzerland), and 56 cages were part of the Trabecular Metal ${ }^{\circledR}$ Acetabular Reconstruction System (TMARS; Zimmer Inc).

\section{Surgical Technique}

With the patient in the lateral decubitus position, a transgluteal, trochanteric slide, or extended trochanteric osteotomy approach was used. Maintaining the continuity of the vastus lateralis and abductors is essential to prevent trochanteric escape and therefore reduce the rate of postoperative limp and nonunion [11, 19].

Table 1. Reason for initial revision to the cup-cage construct

\begin{tabular}{lc}
\hline Reason & Number \\
\hline Loose cup & 51 \\
Loose cage & 8 \\
Second-stage reimplantation for infection & 7 \\
Previous Girdlestone as a result of infection & 1 \\
\hline
\end{tabular}


The surgical technique for the cup-cage construct has been previously described [15]. The acetabular defect is reamed by hemispherical reamers until contact is made with bleeding host bone and the acetabulum is assessed for the need for structural allograft or $\mathrm{TM}^{\mathbb{R}}$ augments. The defect is filled with morcellized bone graft and sized for a $\mathrm{TM}^{\mathbb{R}}$ acetabular cup and an appropriate antiprotrusio cage that spans the defect from ilium to ischium. Screw fixation is used to augment the initial press-fit fixation of the $\mathrm{TM}^{\circledR}$ acetabular cup; new screw holes may be drilled through the trabecular metal of the cup if necessary. The cup is placed vertically and retroverted enough to allow access to the ilium and the ischium for the cage.

Inferior fixation of the cage is obtained by slotting the inferior flange into the ischium, thus reducing the risks of screw fracture, cage migration, and sciatic nerve injury [4]. The superior flange of the cage is secured with screws being careful not to damage the extrapelvic (superior gluteal nerve and artery) or intrapelvic (internal iliac and obturator vessels) structures. Finally, a polyethylene liner is cemented into the cage with the appropriate inclination and version independent of the position of the cage (Fig. 1). All the surgeries were done or directly supervised by a senior orthopaedic surgeon with vast experience in joint reconstruction surgery (AEG).

\section{Postoperative Evaluation}

Postoperatively the patients were clinically evaluated at 6 weeks, 3 months, 6 months, 1 year, and then annually.
The Merle d'Aubigné-Postel score was the primary outcome scoring instrument used and was recorded at each visit [6]. Patients were kept touch weightbearing for 8 weeks using a walker or crutches and then advanced to full weightbearing with one cane that they usually kept for 6 weeks. The only restrictions were flexion beyond $90^{\circ}$ and no active abduction for 6 weeks. An abduction brace was not used.

Radiological evaluation included AP pelvis radiographs and lateral of the affected hip that were taken at 6 weeks, 6 months, and then annually. The initial 6-week postoperative radiographs served as a baseline with which all subsequent radiographs were compared for evidence of migration or loosening of components. The radiographs were evaluated by two of the authors (TA, WAR).

Acetabular migration ( $>5 \mathrm{~mm}$ ) was assessed according to criteria published by Massin et al. [20] and also by the presence of any circumferential radiolucent lines around the acetabular component including the area around the screws. Loosening of the cage was determined according to the Kosashvili modification [15] of Gill et al.'s criteria [10]. The cages were considered to be definitely loose if at least one of three radiological findings was detected: (1) horizontal or vertical migration $>5 \mathrm{~mm}$; (2) a complete and progressive radiolucent line medially and superiorly or around the screws on an AP pelvic radiograph; and (3) breakage of hardware such as flanges or screws. Probable loosening was defined as progressive radiolucency medially or superiorly on an AP pelvic radiograph and possible loosening as a nonprogressive radiolucency, which did not
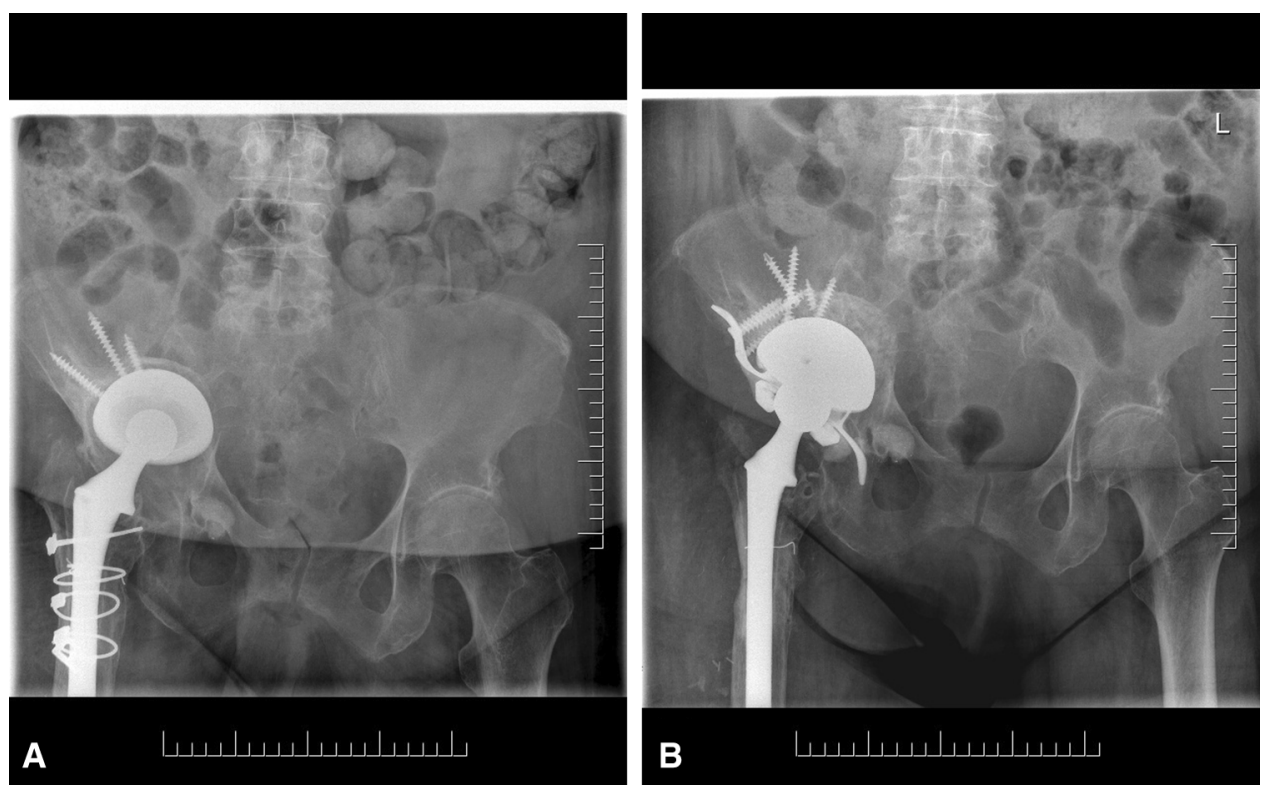

Fig. 1A-B (A) A 78-year-old patient had a Gross Type V (pelvic discontinuity) loose cup. It was reconstructed with a cup-cage and a constrained liner was needed because of insufficient abductors as a

result of previous surgeries. (B) A 5-year followup radiograph of the same patient shows the cup-cage construct in place with no signs of migration or loosening. 
involve the screws. The presence of nonprogressive radiolucency around the tip of the ischial flange, which is a common finding and probably represents micromovement of the flange while biological stabilization of the acetabular component takes place, was not regarded as loosening in our analysis.

Failure was defined as those cup-cage constructs that required revision surgery and replacement of the cup-cage for any reason (including infection).

\section{Statistical Analysis}

SPSS 21 (SPSS Inc, Chicago, IL, USA) was used for data analysis. The Kaplan-Meier survival curve with $95 \%$ confidence interval (CI) was used to assess cup-cage survival. Comparison between curves was done using the GehanBrislow-Wilcoxon test. Preoperative and postoperative Merle d'Aubigné-Postel scores were compared using a paired Student's t-test.

\section{Results}

With clinical failure resulting from any cause as the endpoint, the overall 5-year Kaplan-Meier survival rate for the cup-cage was $93 \%$ (95\% CI, 83.1-97.4) with 38 patients at risk, and the 10-year survival rate was $85 \%$ (95\% CI, 67.293.8) with 11 patients at risk (Fig. 2).

At a mean followup of 68 months (range, 24135 months; SD, 33.4), the revision rate of the 26 cupcages used in the absence of pelvic discontinuity (Type IV defect) was $8 \%$ (two of 26). The revision rate resulting from aseptic loosening was $0 \%$. The 45 cup-cages used for the treatment of pelvic discontinuity (Type $\mathrm{V}$ defect) had a revision rate for any cause of $9 \%$ (four of 45 ) at a mean followup of 77 months (range, 24-135 months; SD, 34.7). The four revisions were the result of aseptic loosening. There was no significant difference between the survival curves of the cup-cage used for Type IV or Type V defects $(\mathrm{p}=1)$.

In our series we had six cup-cage failures. Four of the six failures were the result of aseptic loosening. The mean postoperative time for the failures was 42 months (range, 5-94 months; SD, 34.9) (Table 2).

The Merle d'Aubigné-Postel score improved significantly from a mean of 6 (range, 5-7; SD, 0.7) preoperatively to 13 (range, $10-16$; SD, 1.5) postoperatively as recorded at the most recent visit $(\mathrm{p}<0.001)$. All the patients were last seen within 12 months of the manuscript preparation between June 2013 and June 2014.

Four cup-cages showed radiographic migration. In all four cases, the migration was seen in the ischial flange (three medially and one laterally). However, the flange was still within the ischium in all the cases and no broken screws or failed hardware were identified. These migrated cup-cages have not progressed in the last 3 years of followup. No cups otherwise demonstrated radiological characteristics suggesting possible or probable aseptic loosening.

The complication rate in our series was $12 \%$, and the most common complications found were infection and dislocation (Table 3).

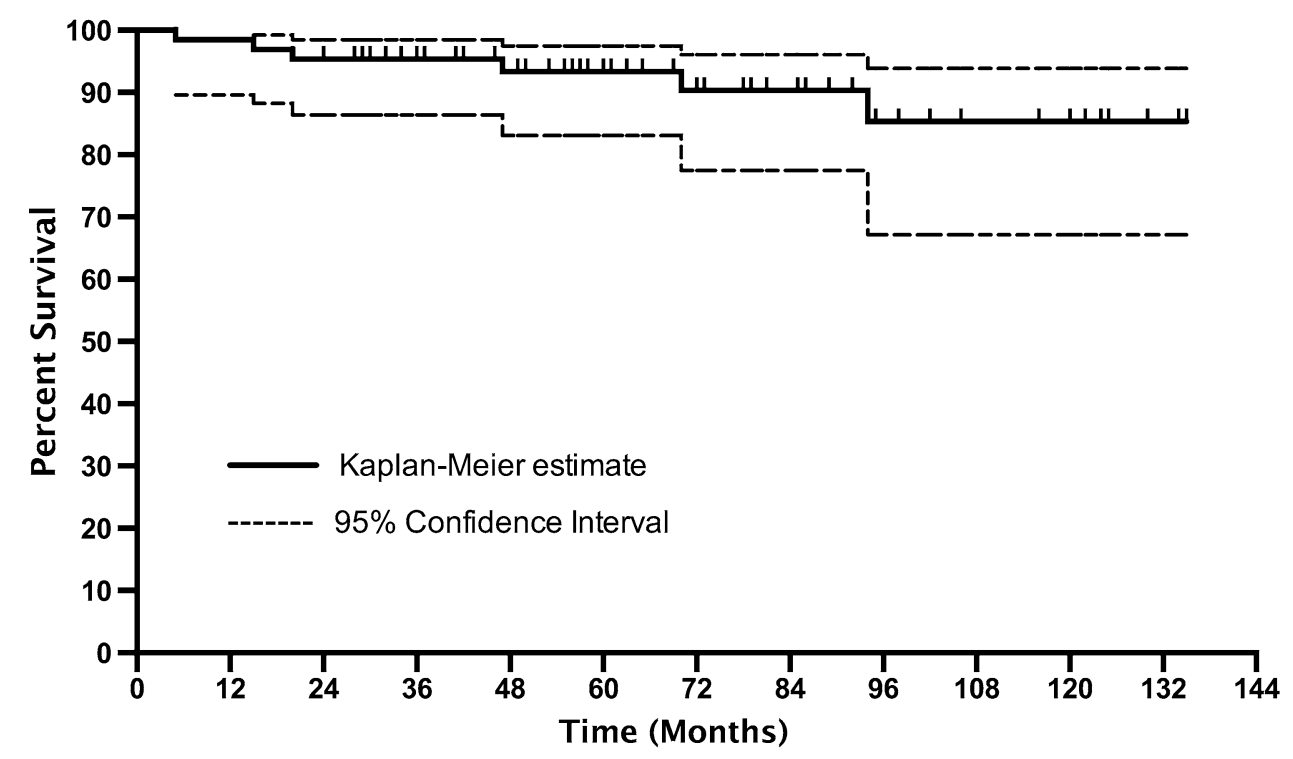

Fig. 2 Kaplan-Meier survival curve (revision for any cause) for the cup-cage with 95\% CI is shown. 
Table 2. Cup-cage failure

\begin{tabular}{|c|c|c|c|}
\hline Failure type & $\begin{array}{l}\text { Time after } \\
\text { Surgery (months) }\end{array}$ & $\begin{array}{l}\text { Pelvic } \\
\text { discontinuity* }\end{array}$ & Treatment \\
\hline Aseptic loosening & 70 & Yes & Revision to cage plus augment \\
\hline Aseptic loosening & 5 & Yes & Revision to cage plus augment \\
\hline Aseptic loosening & 20 & Yes & Revision to cage \\
\hline Aseptic loosening & 94 & Yes & Revision to cage \\
\hline Dislocation & 15 & No & $\begin{array}{l}\text { Open reduction, revision to constrained } \\
\text { liner; dislocated constrained liner, revised to } \mathrm{TM}^{\mathbb{R}} \text { cup and constrained liner }\end{array}$ \\
\hline Septic loosening & 47 & No & $\begin{array}{l}\text { I\&D with liner and head exchange; persistent infection, one-stage revision, } \\
\text { cemented constrained liner }\end{array}$ \\
\hline
\end{tabular}

* Presence of pelvic discontinuity at the initial revision; I\&D = irrigation and débridement.

Table 3. Complications associated with the cup-cage constructs

\begin{tabular}{lll}
\hline Type of complication & Number & Treatment and initial type of acetabular defect \\
\hline Infection & 3 & $\begin{array}{l}\text { Two patients had I\&D and head/liner exchange; no recurrent infection } \\
\text { (one Type IV and one Type V defect); one patient had I\&D and liner } \\
\text { exchange with chronic suppressive antibiotic therapy for infection (Type IV defect) }\end{array}$ \\
$\begin{array}{l}\text { Tislocation } \\
\text { Two patients had open reduction (Type IV defect); one patient had open reduction and } \\
\text { exchange to constrained liner (Type V defect) }\end{array}$ \\
Peroneal distribution (drop foot) treated with orthosis (one Type IV and one Type V defect)
\end{tabular}

$\mathrm{I} \& \mathrm{D}=$ irrigation and débridement.

\section{Discussion}

Significant acetabular defects and pelvic discontinuity remain challenging issues in revision THA. Our study shows that the cup-cage construct is a good alternative for the treatment of such cases. We demonstrated a 10 -year survival rate of $85 \%$ and a significant increase in the Merle d'Aubigné-Postel functional score. Our mid-term results are encouraging and provide a rationale for use of this construct, which relies on the cage for initial stability and biologic fixation of the cup for its long-term stability.

Our study has some limitations. It is a retrospective series with a relatively small number of patients, although it does represent extensive experience with this difficult subset of acetabular deficiencies. The classification of the deficiency at the time of surgery remains somewhat subjective but was performed by the senior surgeon who developed the classification scheme. Only one outcome instrument was used (the Merle d'Aubigné-Postel score), but it was collected at all time periods and it has been previously used to report outcomes after complex revision hip surgery $[18,28]$. Also, all surgeries were done or assisted by this same experienced orthopaedic surgeon and therefore the outcomes cannot be extrapolated. Finally, after multiple revision surgeries with compromised bone stock, most patients are advised to limit their activities in an attempt to preclude further need for surgery and thus cannot be expected to represent the activity level of an ageappropriate normal population.

Taking into account aseptic loosening only, the midterm survival of the 26 cup-cages used for severe bone loss (segmental loss of bone stock $>50 \%$, Gross Type IV) is excellent. In this group all the constructs were solidly fixed at a mean followup of 68 months, providing better results than that reported for $\mathrm{TM}^{\mathbb{R}}$ cups alone and in combination with augments. Lakstein et al. [18] used $\mathrm{TM}^{\mathbb{R}}$ cups in 53 hips with Gross Type IV defects and reported a revision rate of $4 \%$ for aseptic loosening at a mean followup of 53 months and Sternheim et al. [29] in the same series reported an $8 \%$ revision rate at a mean followup of 72 months. Additionally, Lachiewicz and Soileau [17] used $\mathrm{TM}^{\circledR}$ cups for acetabular revision in 39 hips and had a repeat revision rate of $3 \%$ at a mean followup of 3 years; however, only 26 of the 39 hips had Paprosky Type 3 acetabular defects. Another option to address the bonedeficient acetabulum is $\mathrm{TM}^{\circledR}$ augments that can be used to fill bone defects and give support to the acetabular component. Del Gaizo et al. [7] reported results in 37 hips with Paprosky 3 defects. All were treated with the $\mathrm{TM}^{\circledR}$ cup and augments and at an average followup of 60 months; the revision rate for aseptic loosening was 3\%. Abolghasemian et al. [1] also reported good results in the revision of Gross 
Type III and IV defects with the $\mathrm{TM}^{\circledR}$ cup and augments. In 32 hips at a mean followup of 64 months, the aseptic loosening revision rate was $3 \%$.

Pelvic discontinuity is a rare problem that represents a separation of the ilium proximally from the ischiopubic segment distally. Usually in the revision setting it happens as a result of osteolytic bone loss. In this scenario, the orthopaedic surgeon needs to restore continuity of the acetabulum, graft any bony deficiencies, optimize contact of remaining viable bone to component surfaces with ingrowth potential, and obtain a mechanically stable reconstruction [24]. In the present series we report a revision rate of $9 \%$ in the pelvic discontinuities treated with a cup-cage construct. These mid-term results are encouraging and much better than the ones previously obtained with the use of cages, which have had revision rates at 3 years between $30 \%$ and $50 \%$ [2, 12]. Previous publications from the same institution with shorter followup have also shown good results with the use of the cup-cage for treatment of pelvic discontinuity. Rogers et al. [25] had a 5\% rate of revision for aseptic loosening in 42 hips with chronic pelvic discontinuity at an average followup of 32 months. Kosashvili et al. [15] reported $11 \%$ revision rate at a mean followup of 44 months.

Pelvic discontinuity has been addressed in the past with the use of ilioischial cages. However, newer techniques such as cup-cage constructs, TriFlange cups (DePuy Orthopaedics, Inc, Warsaw, IN, USA), and acetabular distraction with $\mathrm{TM}^{\mathbb{R}}$ cups have emerged as better options. Taunton et al. [31] reported his results with the use of the TriFlange in 57 hips. At a mean followup of 65 months, the revision rate for aseptic loosening was $2 \%$. Nonetheless, the failure rate for any cause was $5 \%$ and 12 of 57 hips (21\%) required head and liner exchange, primarily because of instability. Also, Sporer et al. [28], using acetabular distraction and reconstruction with the $\mathrm{TM}^{\mathbb{R}}$ cup in 20 hips with a mean followup of 5 years, reported an aseptic loosening revision rate of $5 \%$.

We found a significant increase in the postoperative Merle d'Aubigné-Postel functional score in our study. Other authors have reported similar improvements in functional scores after revision hip surgery; Lakstein et al. [18] reported a significant improvement to a postoperative Merle d'Aubigné-Postel score of 10.6 with the use of TM $^{\mathbb{R}}$ cups for complex acetabular defects. In his pelvic discontinuity series treated with a distraction technique, Sporer et al. [28] reported a significant increase in Merle d'Aubigné-Postel functional score from 3.3 to 9.6 after the revision surgery. In addition, several series report improvement of functional scores such as the Harris hip score or Oxford hip score after hip revision surgeries with the mentioned techniques $[1,7,15,17,31]$.
Ischial flange migration was noted in four cup-cages, two of which were in the pelvic discontinuity group. However, these cup-cage constructs seem to be stable because they have not progressed in the last 3 years. Nonprogressive migration is commonly reported in other series involving complex acetabular revision. Taunton et al. [31] reported it in 14\% of their TriFlange cups in pelvic discontinuity settings, and Sporer et al. [28] found nonprogressive stable migration in $21 \%$ of their patients treated with acetabular distraction and $\mathrm{TM}^{\circledR}$ cups.

The complication rate in our series was $12 \%$. Although this number might seem high, it is important to take into account that these cases are very complex procedures with several previous surgeries. The previously reported complication rate for complex acetabular revisions treated with $\mathrm{TM}^{\circledR}$ with or without augments ranges from $5 \%$ to $20 \%[1$, $7,17,18]$. Additionally, in series treating pelvic discontinuities, the complication rate ranged from $16 \%$ to $29 \%[25$, 28, 31].

\section{Conclusion}

Our study shows good mid-term results with the use of the cup-cage for pelvic discontinuity and large acetabular defects. We found that the cup-cage had a good survival rate, good clinical outcomes, and a low complication rate. We believe that for the treatment of severe acetabular bone defects, the use of a cup-cage is an excellent and reliable option if stable fixation cannot be obtained through the use of a $\mathrm{TM}^{\mathbb{R}}$ cup with or without augments. The cup-cage construct remains an excellent choice to treat chronic pelvic discontinuity. However, these revisions can be technically complex, requiring careful preoperative planning and appropriate knowledge of the surgical technique.

\section{References}

1. Abolghasemian M, Tangsataporn S, Sternheim A, Backstein D, Safir O, Gross AE. Combined trabecular metal acetabular shell and augment for acetabular revision with substantial bone loss. A mid-term review. Bone Joint Surg. 2013;95:166-172.

2. Berry DJ, Lewallen DG, Hanssen AD, Cabanela ME. Pelvic discontinuity in revision total hip arthroplasty. J Bone Joint Surg Am. 1999;81:1692-1702.

3. Bobyn JD, Stackpool GJ, Hacking SA, Tanzer M, Krygier JJ. Characteristics of bone ingrowth and interface mechanics of a new porous tantalum biomaterial. $J$ Bone Joint Surg Br. 1999;81:907-914.

4. Chahal J, McCarthy T, Safir O, Kosashvili Y, Gross AE. Late presentation of sciatic neuropathy after failure of acetabular reconstruction rings in revision hip arthroplasty: a report of two cases. Curr Orthop Pract. 2008;19:688-690.

5. Cohen R. A porous tantalum trabecular metal: basic science. Am J Orthop. 2002;31:216-217. 
6. d'Aubigné RM, Postel M. Functional results of hip arthroplasty with acrylic prosthesis. J Bone Joint Surg Am. 1954;36:451-475.

7. Del Gaizo DJ, Kancherla V, Sporer SM, Paprosky WG. Tantalum augments for Paprosky IIIA defects remain stable at midterm followup. Clin Orthop Relat Res. 2012;470:395-401.

8. Della Valle CJ, Berger RA, Rosenberg AG, Galante JO. Cementless acetabular reconstruction in revision total hip arthroplasty. Clin Orthop Relat Res. 2004;420:96-100.

9. Della Valle CJ, Shuaipaj T, Berger RA, Rosenberg AG, Shott S, Jacobs JJ, Galante JO. Revision of the acetabular component without cement after total hip arthroplasty. A concise follow-up, at fifteen to nineteen years, of a previous report. J Bone Joint Surg Am. 2005;87:1795-1800.

10. Gill TJ, Sledge JB, Muller ME. The Burch-Schneider anti protrusion cage in revision total hip arthroplasty: indications, principles and long term results. J Bone Joint Surg Br. 1998;80:946-953.

11. Goodman S, Pressman A, Saastamoinen H, Gross A. Modified sliding trochanteric osteotomy in revision total hip arthroplasty. $J$ Arthroplasty. 2004;19:1039-1041.

12. Goodman S, Saastamoinen H, Nadav S, Gross A. Complications of ilioischial reconstruction rings in revision total hip arthroplasty. J Arthroplasty. 2004;19:436-446.

13. Gross AE, Goodman SM. The use of cages in revision arthroplasty of the acetabulum. In: Berry DJ, Trousdale RT, Dennis DA, Paprosky WG, eds. Revision Total Hip and Knee Arthroplasty. Philadelphia, PA, USA: Lippincott Williams \& Wilkins; 2012:179.

14. Hacking SA, Bobyn JD, Toh K, Tanzer M, Krygier JJ. Fibrous tissue ingrowth and attachment to porous tantalum. J Biomed Mater Res. 2000;52:631-638.

15. Kosashvili Y, Backstein D, Safir O, Lakstein D, Gross AE. Acetabular revision using an anti-protrusion (ilio-ischial) cage and trabecular metal acetabular component for severe acetabular bone loss associated with pelvic discontinuity. J Bone Joint Surg Br. 2009;91:870.

16. Kosashvili Y, Safir O, Backstein D, Lakstein D, Gross AE. Salvage of failed acetabular cages by nonbuttressed trabecular metal cups. Clin Orthop Relat Res. 2010;468:466-471.

17. Lachiewicz PF, Soileau ES. Tantalum components in difficult acetabular revisions. Clin Orthop Relat Res. 2010;468:454-458.

18. Lakstein D, Backstein D, Safir O, Kosashvili Y, Gross AE. Trabecular Metal cups for acetabular defects with $50 \%$ or less host bone contact. Clin Orthop Relat Res. 2009;467:2318-2324.

19. Langlais F, Lambotte JC, Collin P, Langlois F, Fontaine JW, Thomazeau H. Trochanteric slide osteotomy in revision total hip arthroplasty for loosening. J Bone Joint Surg Br. 2003;85:510516.

20. Massin P, Schmidt L, Engh CA. Evaluation of cementless acetabular component migration: an experimental study. J Arthroplasty. 1989;4:245-251.
21. Meneghini RM, Ford KS, McCollough CH, Hanssen AD, Lewallen DG. Bone remodeling around porous metal cementless acetabular components. J Arthroplasty. 2010;25:741-747.

22. Meneghini RM, Hanssen AD, Lewallen DG. Uncemented hemispherical cups in extreme bone loss. In: Berry DJ, Trousdale RT, Dennis DA, Paprosky WG, eds. Revision Total Hip and Knee Arthroplasty. Philadelphia, PA, USA: Lippincott Williams \& Wilkins; 2012:163.

23. Perka C, Ludwig R. Reconstruction of segmental defects during revision procedures of the acetabulum with the Burch-Schneider anti-protrusio cage. J Arthroplasty. 2001;16:568-574.

24. Petrie J, Sassoon A, Haidukewych GJ. Pelvic discontinuity: current solutions. Bone Joint J. 2013;95(Suppl A):109-113.

25. Rogers BA, Whittingham-Jones PM, Mitchell PA, Safir OA, Bircher MD, Gross AE. The reconstruction of periprosthetic pelvic discontinuity. J Arthroplasty. 2012;27:1499-1506.

26. Saleh K, Holtzman J, Gafni A, Saleh L, Davis A, Resig S, Gross AE. Reliability and intraoperative validity of preoperative assessment of standardized plain radiographs in predicting bone loss at revision hip surgery. $J$ Bone Joint Surg Am. 2001;83:1040-1046.

27. Saleh KJ, Jaroszynski G, Woodgate I, Saleh L, Gross AE. Revision total hip arthroplasty with the use of structural acetabular allograft and reconstruction ring: a case series with 10 year average follow-up. J Arthroplasty. 2000;15:951-958.

28. Sporer SM, Bottros JJ, Hulst JB, Kancherla VK, Moric M, Paprosky WG. Acetabular distraction: an alternative for severe defects with chronic pelvic discontinuity? Clin Orthop Relat Res. 2012;470:3156-3163.

29. Sternheim A, Backstein D, Kuzyk PR, Goshua G, Berkovich Y, Safir O, Gross AE. Porous metal revision shells for management of contained acetabular bone defects at a mean follow-up of six years: a comparison between up to $50 \%$ bleeding host bone contact and more than $50 \%$ contact. J Bone Joint Surg Br. 2012;94:158-162.

30. Tangsataporn S, Abolghasemian M, Kuzyk PR, Backstein DJ, Safir OA, Gross AE. Salvaged failed roof rings and antiprotrusion cages: surgical options and implant survival. Hip Int. 2013;23:166-172.

31. Taunton MJ, Fehring TK, Edwards P, Bernasek T, Holt GE, Christie MJ. Pelvic discontinuity treated with custom triflange component: a reliable option. Clin Orthop Relat Res. 2012;470:428-434.

32. Weeden SH, Paprosky WG. Porous-ingrowth revision acetabular implants secured with peripheral screws. A minimum twelve-year follow-up. J Bone Joint Surg Am. 2006;88:1266-1271.

33. Zhang Y, Ahn PB, Fitzpatrick DC, Heiner AD, Poggie RA, Brown TD. Interfacial frictional behavior: cancellous bone, cortical bone and a novel porous tantalum biomaterial. $J$ Bone Joint Surg Br. 1999;3:245-251. 